\title{
Decision support systems for efficient irrigated agriculture
}

\author{
R. Oad, L. Garcia, K.-D. Kinzli \& D. Patterson \\ Department of Civil Engineering, Colorado State University, \\ Fort Collins, Colorado, USA
}

\begin{abstract}
Water is the lifeblood of the American West and the foundation of its economy, but it remains its scarcest resource. The explosive population growth in western urban areas, the emerging need for water for environmental and recreational uses, and the national importance of the domestic food production from western farms are driving major conflicts between these competing water uses (US Department of Interior, 2003). Irrigated agriculture in particular is by far the largest water user $-80 \%$ countrywide and $90 \%$ in the Western U.S - and since it is perceived to be a comparatively inefficient user, it is frequently asked to decrease its water consumption. Irrigated agriculture in the Middle Rio Grande diverts large quantities of river water, which is believed to leave insufficient water to meet other societal needs such as urban and wildlife requirements. This paper will present our research on options to make irrigation system operations more efficient. Most irrigation systems can meet their users' needs with decreased river diversions by adopting operational procedures, which are based on real-time knowledge of available water supplies and crop water requirements. The paper will describe our on-going research in the Middle Rio Grande Valley, to develop a Decision-Support System (DSS) that can assist water managers to closely match water deliveries to crop water requirements, thereby reducing river diversions. The DSS uses linear programming logic with an objective function to find an optimum water delivery schedule for the service areas in an irrigation system. Water delivery using the DSS is accomplished using three modules: a water demand module, a supply network module and an irrigation scheduling module. Limited field validation shows that the DSS is indeed able to correctly model the irrigation delivery system, and recommend water delivery schedules that are reasonable. Future plans include more intensive field validation and implementation in the Middle Rio Grande irrigation service area.

Keywords: irrigated agriculture, decision support systems, competing water uses, operational procedures, ecology, wildlife habitat, rotational water delivery.
\end{abstract}




\section{Introduction}

Irrigated agriculture in the Western United States has traditionally been the backbone of the rural economy. The climate in the American West with average annual rainfall of $20-38 \mathrm{~cm}$ is such that dry land farming is not an option in most areas. Topography in the West is characterized by the Rocky Mountains which accumulate significant snowfall every year. Snowmelt in the Rockies results in considerable surface water, of which irrigated agriculture uses roughly 80 to $90 \%$. Along with water quantity issues, irrigated agriculture causes water quality degradation through surface runoff and return flow laden with sediment, agricultural fertilizers, and pesticides. Managing salinity in irrigation districts in the West is a poignant concern due to the fact that $17 \%$ of the world's arable land has been lost to salinization. Along with degradation in water quality, wildlife concerns need to be addressed. The combined demands of agriculture, urban, and industrial sectors leave little water for fish and wildlife. Flows in many western rivers have become so minimal that rivers actually go dry from diversions and fish and wildlife become threatened. Since irrigated agriculture uses roughly 80 to $90 \%$ of surface water in the West it is often targeted to decrease diversions. Due to wildlife concerns and demands from an ever growing urban population, the pressure for flow reductions on irrigated agriculture increases every year. In order to sustain itself and deal with outside pressure for reduced river diversions irrigated agriculture has to become more efficient in overall water consumption. This paper focuses on research regarding improving water delivery operations in the Middle Rio Grande irrigation system through the use of a decision support system.

\subsection{Middle Rio Grande Valley}

The Middle Rio Grande (MRG) Valley runs north to south through central New Mexico from Cochiti Reservoir to the headwaters of Elephant Butte Reservoir, a distance of approximately 175 miles. The valley is narrow, with the majority of water use occurring within five miles on either side of the river. The bosque, or riverside forest of cottonwood and salt cedar, is supported by waters of the Rio Grande. Surrounding the bosque is widespread irrigated farming. The City of Albuquerque and several smaller communities are located in and adjacent to the MRG Valley. Although the valley receives less than 10 inches of rainfall annually, it supports a rich and diverse ecosystem of fish and wildlife and is a common resource for communities in the region.

Water supply available for use in the MRG Valley includes: native flow of the Rio Grande and its tributaries, allocated according to the Rio Grande Compact of 1938; San Juan-Chama (SJC) project water, obtained via a transmountain diversion from the Colorado River system; and groundwater. Water is fully appropriated in the MRG Valley and its utilization is limited by the Rio Grande Compact. The Compact sets forth a schedule of deliveries of native Rio Grande water from Colorado to New Mexico and from New Mexico to Texas. 


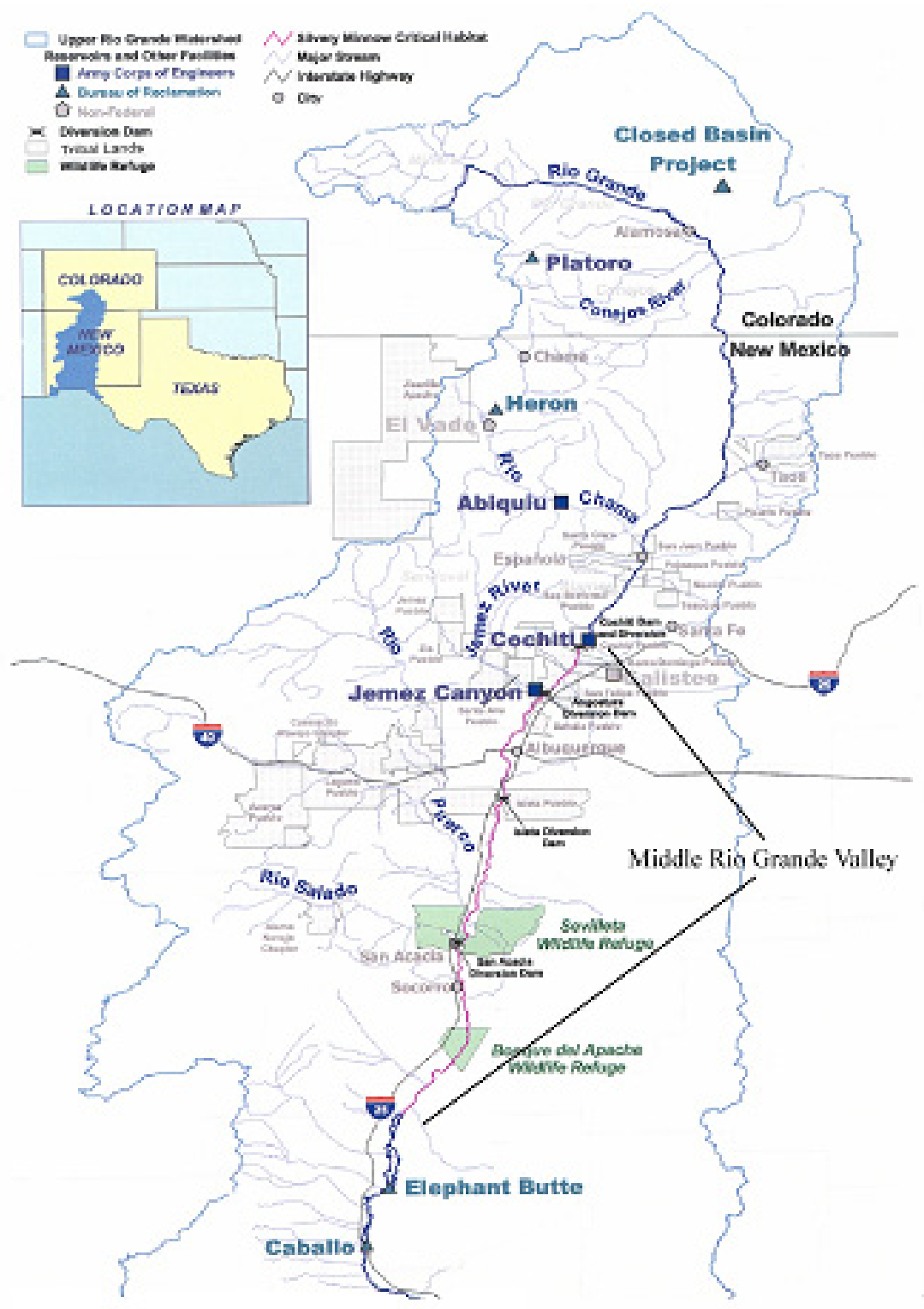

Figure 1.

Water demand in the MRG Valley includes irrigated agriculture in the MRGCD (Middle Rio Grande Conservancy District) and Indian Lands, and municipal and industrial consumption. In addition to these demands, there are significant consumptive uses associated with riparian vegetation, and wetland, river, and reservoir evaporation. Superimposed on these demands are river flow 
targets associated with two federally-listed endangered species, the silvery minnow (hybognathus amarus), and the southwestern willow fly catcher (Empidonax traillii extimus).

\subsection{Middle Rio Grande Conservancy District}

The MRGCD was formed in 1925 in response to flooding and the deterioration of irrigation works. Water diverted by the MRGCD originates as native flow of the Rio Grande and its tributaries, including the Rio Chama. The MRGCD services irrigators from Cochiti Reservoir to the northern boundary of the Bosque del Apache National Wildlife Refuge. Irrigation facilities managed by the MRGCD divert water from the river to service agricultural lands, which include small urban parcels and large tracts that produce alfalfa, pasture, corn and vegetable crops. The diversity of users includes: six Indian pueblos, large farm parcels, community ditch associations, independent acequia communities and urban landscape irrigators. The MRGCD supplies water to its four divisions -- Cochiti, Albuquerque, Belen and Socorro -- through Cochiti Dam and Angostura, Isleta and San Acacia diversion weirs, respectively. In addition to direct diversions at these weirs, all divisions except Cochiti receive return flow via drains from divisions upstream. Water is conveyed in the MRGCD by gravity flow through primarily earthen ditches. Water is delivered to users in a hierarchical manner: it is typically diverted from the river into a main canal, to secondary canal or lateral, and eventually into the farm ditch. After water is conveyed through laterals, it is delivered to the farm through a turnout structure, often with a check structure in the lateral canal. On-farm water management is entirely the responsibility of water users. The method of application is typically surface (flood) irrigation, either basin or furrow.

The MRGCD does not meter individual farm turnouts; rather, ditch-riders estimate water delivery on the basis of time required for irrigation. Prior to the recent drought, to provide flexible and reliable water delivery to users on a continuous basis, MRGCD operated the main canals and laterals near full capacity, so water supply was always greater than perceived demand. However, the practice resulted in large water diversions from the river. During the recent drought years, the MRGCD has taken a proactive approach to be a more efficient water user and service its irrigators with reduced river diversions. Towards this end, the division managers and ditch-riders are increasingly practicing rotational water delivery, which is an effective way to fulfill demand with reduced available water.

Rotational Water Delivery (RWD) is used in irrigation systems worldwide to improve water delivery and to support water conservation. In RWD, lateral canals receive water from the main canal by turns, allowing water use in some laterals while others are closed. In addition to this water rotation among laterals, there can be rotation within laterals whereby water use is distributed in turns among farm turnouts or check structures along a lateral. By distributing water among users in a systematic rotational fashion, an irrigation district can decrease water diversions and still meet crop water use requirements. A well-managed 
program of rotational water delivery is able to fulfill seasonal crop water requirements in a timely manner, but requires less water than continuous water delivery.

\section{Decision support modelling of irrigation systems}

The New Mexico Interstate Stream Commission and the MRGCD have sponsored a research project with Colorado State University to develop a DSS, to model and assist implementation of rotational water delivery in the MRGCD's service area. A DSS combines intellectual resources of individuals with capabilities of computers to improve the quality of decision-making. It is a logical arrangement of information including engineering models, field data, GIS and graphical user interfaces, and is used by managers to make informed decisions. In irrigation systems, a DSS can organize information about water demand in the service area and then schedule available water supplies to efficiently fulfill the demand.

The conceptual problem addressed by a DSS for an irrigation system, then, is: how best to route water supply in a main canal to its laterals so that the required water diversion is minimized. The desirable solution to this problem should be "demand-driven", in the sense that it should be based on a realistic estimation of water demand. The water demand in a lateral canal service area, or for an irrigated parcel, can be predicted throughout the season through analysis of information on the irrigated area, crop type and soil characteristics. The important demand concepts are: When is water supply needed to meet crop demand (Irrigation Timing), How long is the water supply needed during an irrigation event (Irrigation Duration), and How often must irrigation events occur for given service area (Frequency of Irrigation).

Decision support systems have found implementation throughout the American West and are mostly used to regulate river flow. Decision support systems on the river level are linked to gauging stations and are used to administer water rights at diversions points. Although decision support systems have proved their worth in river management, few have been implemented for modeling irrigation canals and laterals. The research presented in this paper has focused on developing, calibrating, validating and eventually implementing a decision support system capable of modeling flow on a canal and lateral level, with the overall goal of efficient irrigation water delivery.

\section{Formulation of decision support system for the Middle Rio Grande}

The DSS was formulated using linear programming with the use of an objective function. Overall model structure consists of three modules that function in tandem to calculate the most efficient irrigation water delivery. 


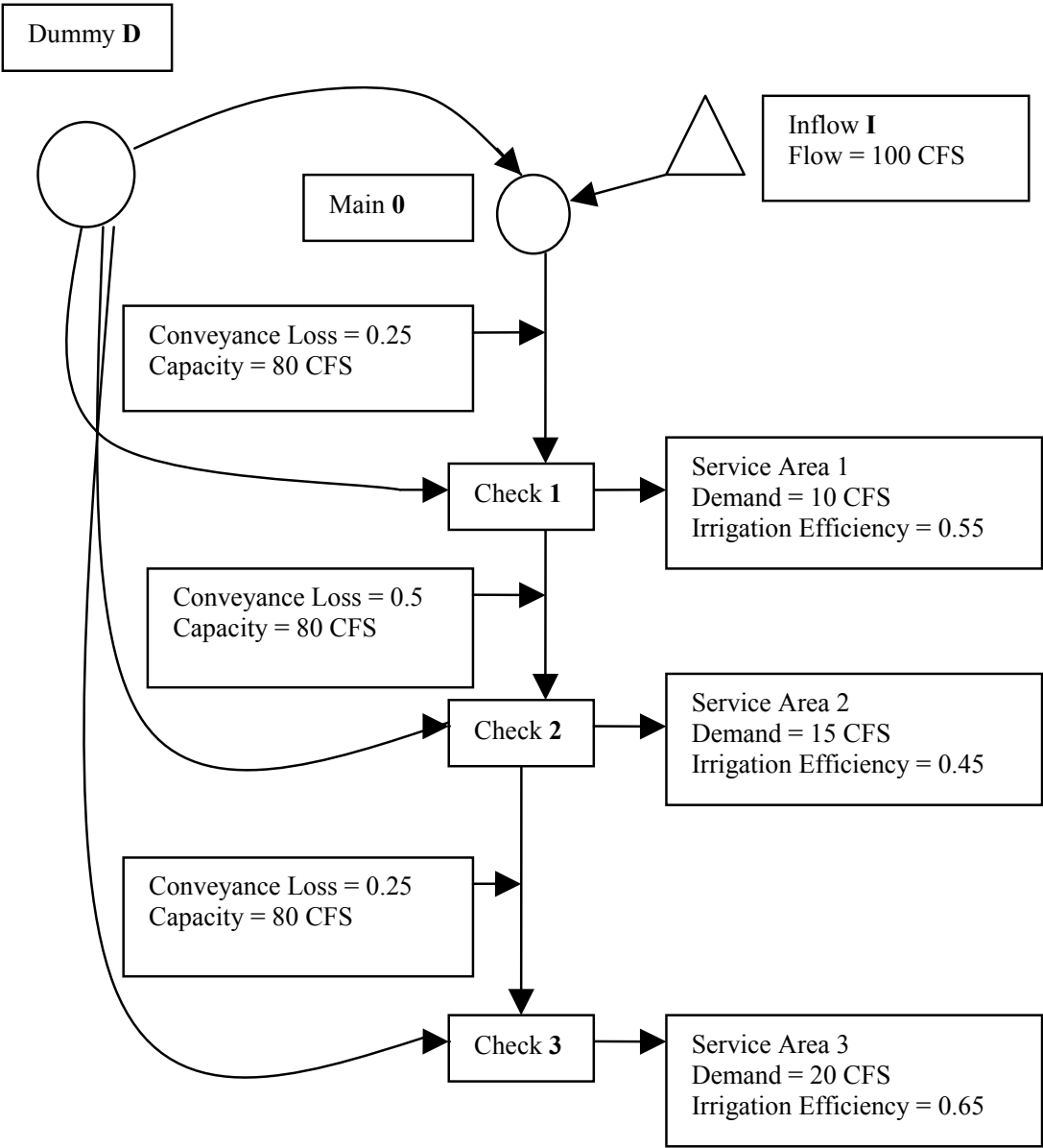

Figure 2.

\subsection{Model programming}

Programming in the model was developed using an objective function to schedule water deliveries to lateral service areas. Constraints on variables within the objective function are specified and must be satisfied in determining the optimum solution. This process achieves the result that water delivery to laterals with more immediate water needs is favored, and delivery to laterals that have sufficient water in a given time step is minimized.

$$
\text { Minimize } Z=\mathrm{MP}_{\mathrm{D}-0} \mathrm{X}_{\mathrm{D}-0}+\mathrm{MP}_{\mathrm{D}-1} \mathrm{X}_{\mathrm{D}-1}+\mathrm{MP}_{\mathrm{D}-2} \mathrm{X}_{\mathrm{D}-2}+\mathrm{MP}_{\mathrm{D}-3} \mathrm{X}_{\mathrm{D}-3}
$$

where $\mathrm{Z}$ is the sum of a modified priority (MP) multiplied by amount of supply (X) from the dummy supply to each demand node. The subscripts refer to the 
nodal points between which flow occurs, i.e., $\mathrm{X}_{\mathrm{D}-1}$ refers to flow from the Dummy supply to Check 1 , and MP ${ }_{\mathrm{D}-1}$ refers to the modified priority of demand to be satisfied at Check 1 from the Dummy supply node. The MP value reflects the need-based ranking system where demand nodes with lower available soil moisture are favored for irrigation. The objective function is solved in conjunction with a system of mass balance equations representing the actual water (and dummy water) delivered to demand nodes, along with other physically-based constraints.

\subsection{Model structure}

The DSS consists of three elements; a water demand module, a supply network, and a scheduling program. A Graphical User Interface (GUI) provides a means for linking the three elements of the DSS. This GUI constitutes a framework for the DSS that provides the user with the ability to access data and output for the system. The three DSS model components are termed modules. The project GIS and databases are used to develop input for both the water demand and the supply network modules. Some of the input is directly linked through the GUI and some is handled externally in this DSS version.

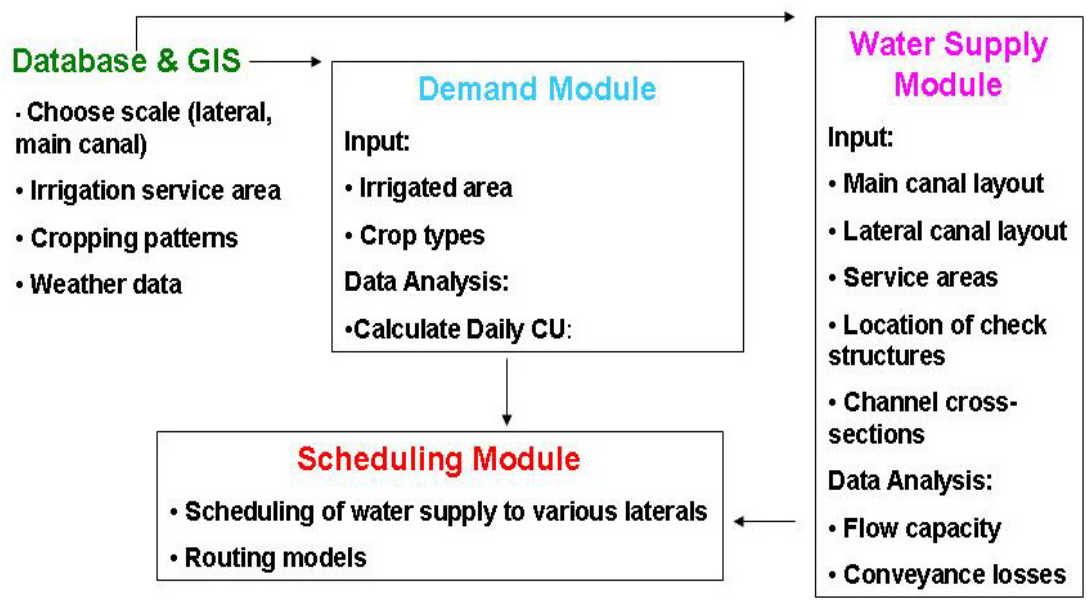

Figure 3.

\subsection{Water demand module}

The water demand module of the MRGCD DSS is implemented through the Integrated Decision Support Consumptive Use, or IDSCU model, a model developed over a period of years by Colorado State University. The IDSCU model consists of a Graphical User Interface (GUI) written in Visual $\mathrm{C}++$ and 
program calculations implemented with FORTRAN. The IDSCU model offers numerous features and options and calculates the following; crop consumptive use (CU), crop irrigation requirement (CIR), and readily available moisture (RAM), as a capacity. The latter two variables, CIR and RAM (as a capacity), are subsequently used in the supply network module. Crop consumptive use is calculated using the Penman-Montieth Method. The reference ET is calculated using weather data from the MRGCD. Crop coefficients using growing degree days are applied to the Penman-based ET to obtain a consumptive use for each crop type throughout the growing season. The water demand module performs these calculations to obtain a spatially-averaged consumptive use at the lateral service area level, using the distribution of crop types within each service area. The crop irrigation requirement (CIR) is calculated by accounting for the effective precipitation using the Soil Conservation Service Method (USDA, [8]). The crop irrigation requirement is calculated on a daily basis, corresponding to the water needed to directly satisfy crop needs for all acres in the service area. The crop irrigation requirement for the service area is subsequently passed to the supply network module, where it is divided by an efficiency factor to obtain a lateral service area delivery requirement (LDR).

Based on acreages, crop types and soil types within each lateral service area, a RAM is calculated. The RAM calculated in this context represents a storage capacity to be filled and depleted over several irrigation cycles during the course of the irrigation season. During each irrigation, it is expected that an amount of water equal to the RAM will be stored in soils. Then, as crops utilize water, the RAM will become depleted.

\subsection{Supply network module}

The supply network module represents the layout of the conveyance system, its physical properties, supply to the conveyance network, and the relative location of diversions from the network to the lateral service area. The layout of the conveyance system is specified through a user-designed link-node network. Through the DSS GUI, a user can drag and drop different types of nodes such as inflows, demands and return flow nodes. The link-node network represents the connections between canals or laterals and demands for water at each service area.

\subsection{Irrigation scheduling module}

The irrigation scheduling module can be used to plan water deliveries to meet crop demand at the lateral and at the main canal level. The module calculates and displays a rotational schedule for the laterals on a given main canal. This schedule indicates how many laterals can be run at a time, how long each lateral should run and how often. The module is currently set up to run on a daily time step. This module calculates the daily irrigation schedule using mass balance equations and the linear programming solver. The approach is based on the consideration that the farm soil root-zone is a reservoir for water storage, for which irrigation applications are inflows and CIR is an outflow. 


\section{Field testing and validation}

Field testing and validation of the MRGCD DSS was conducted during the summer of 2005. Initial calibration was performed and examined the irrigated acreages and crop distribution represented by the model. The acreages used by the model were adjusted to match GIS coverages of irrigated acreage and crop type. System infrastructure data was also collected during 2005 to insure accurate representation of the distribution network. Canal capacity measurements were made to represent actual canal carrying capacities in the DSS. To calibrate the model, a sensitivity analysis was performed on the main input variables. Sensitivity analysis consisted of varying one single variable while keeping all other variables constant. Using the sensitivity analysis the model input parameters were calibrated.

To validate and field test the rotation set forth by the DSS, the DSS rotation was compared to the rotational procedure implemented by MRGCD ditch-riders for a small portion of the MRGCD. Field testing of the irrigation rotation, using the input parameters determined during the calibration, was done on two laterals. The average required irrigation flow, average irrigation duration, and average irrigation frequency from the model were compared to data collected in the field. Average irrigation flows, as well as average irrigation duration, were modeled well and little discrepancy between the model and actual practice exists. Model values for irrigation frequency were slightly higher than the values from actual practice. The reason for this could be that during actual practice, irrigation events occur before the RAM is significantly depleted. It was observed on several occasions during the summer of 2005 that alfalfa fields were irrigated every ten days. Irrigation of alfalfa every ten days is excessive and would account for the shorter irrigation frequency recorded from the field data. Overall, the irrigation frequency developed by the model is reasonable within the limits set forth by the MRGCD.

When comparing the required irrigation flow, irrigation duration, and frequency of irrigation, the results from the model compare well with the actual data. Overall the schedule developed by the DSS is reasonable and accurately matches conditions in the field.

\section{Conclusions and further research}

A decision support system for the Middle Rio Grande Conservancy District was developed that models canal network systems and can compute water delivery options for optimum water use. Using three modules the model represents water demands, the irrigation network, and water scheduling aspects of irrigation. The model is fully capable of developing schedules for rotational water delivery in the MRGCD and evaluation has shown that model recommendations are realistic and represent ditch-rider rotational practice.

Future work on the DSS will entail an in depth field investigation of model adequacy and eventually the full implementation of the model. Model adequacy 
will be tested by closely monitoring fluctuations in RAM during a period where the rotational schedule from the model is used exclusively. By determining whether the model effectively manages the moisture in the root zone, revisions and improvements to the model can be made. Once field investigations are complete the finalized model can be implemented for rotational scheduling throughout the entire MRGCD. By implementing the DSS for rotational scheduling the MRCGD will reduce river diversions and can continue to sustain irrigated agriculture in the Middle Rio Grande Valley.

\section{References}

[1] Barta, R. 2003. Improving Irrigation System Performance in the Middle Rio Grande Conservancy District. Masters Thesis. Department of Civil Engineering, Colorado State University. Fort Collins, Colorado.

[2] DuMars, C.T. and S.C. Nunn (eds.). 1993. Working Document: Middle Rio Grande Conservancy District Water Policies Plan. Middle Rio Grande Conservancy District. Albuquerque, New Mexico.

[3] King, J.P., A.S. Bawazir, and T.W. Sammis. 2000. Evapotranspiration Crop Coefficients as a Function of Heat Units for Some Agricultural Crops in New Mexico. New Mexico Water Resources Research Institute. Technical Completion Report. Project No. 01-4-23955.

[4] Oad, Ramchand and R. Barta (2003). Managing Irrigated Agriculture for Better River Ecosystems-A Case Study of the Middle Rio Grande. Paper presented at the Second International Conference on Irrigation and Drainage, USCID, Phoenix, Arizona, May 12-15, 2003.

[5] Rio Grande Compact Commision. 1997. Report of the Rio Grande Compact Commision, 1997.

[6] S.S. Papadopulos and Associates, Inc. (SSPA). 2002. Evaluation of the Middle Rio Grande Conservancy District Irrigation System and Measurement Program. Boulder, Colorado.

[7] United States Fish and Wildlife Service (USFWS). 2003. Federal Register 50 CFR Part 17. Endangered and Threatened Wildlife and Plants; Designation of Critical Habitat for the Rio Grande Silvery Minnow; Final Rule. Vol. 68, No. 33. U.S. Department of Interior.

[8] United States Department of Agriculture (USDA) 1967. Manual of Irrigation Requirements Technical Paper 21. Washington D.C. 